\title{
Preparation of Yttrium-based Rare Earth Conversion Coating and Its Effect on Corrosion Resistance of AZ91D Magnesium Alloy
}

\author{
Baojun Han ${ }^{1,2, *}$, Dongdong $\mathrm{Gu}^{2}$, Yang Yang ${ }^{2}$, Ling Fang ${ }^{1,2}$, Guanghuai Peng ${ }^{1,2}$, Chubin Yang ${ }^{1,2}$ \\ ${ }^{1}$ Jiangxi Provincial Engineering Research Center for Magnesium alloys, GanNan Normal University, \\ Ganzhou 341000, PR China \\ ${ }^{2}$ School of Chemistry and Chemical Engineering, GanNan Normal University, Ganzhou 341000, PR \\ China \\ *E-mail: bao77junhan@yahoo.com
}

doi: $10.20964 / 2017.01 .53$

Received: 10 October 2016 / Accepted: 16 November 2016 / Published: 12 December 2016

\begin{abstract}
The yttrium-based rare earth conversion coating on the surface of AZ91D magnesium alloy was prepared and post-treated by simple immersing in solution of yttrium nitrate $\left(\mathrm{Y}\left(\mathrm{NO}_{3}\right)_{3}\right)$ and silica sol. The micro-morphology, transverse section and composition of the coatings were investigated by scanning electron microscopy (SEM), energy dispersive spectroscopy (EDS) and X-ray photoelectron spectroscopy (XPS), respectively. The corrosion resistance was assessed by means of potentiodynamic polarization curves, immersion testing and electrochemical impedance spectroscopy (EIS). The results show that the coating is mainly composed of $\mathrm{Y}_{2} \mathrm{O}_{3}, \mathrm{YOx} / \mathrm{y}, \mathrm{Al}_{2} \mathrm{O}_{3}$ and $\mathrm{MgO}$, and the post-treated yttrium-based rare earth conversion coating was homogeneous and uniform in morphology. The corrosion resistance capability of the coated AZ91D magnesium alloy was obviously improved compared with the bare one. The corrosion potential shifted positively about $230 \mathrm{mV}$, and the corrosion current density decreased about two orders of magnitude.
\end{abstract}

Keywords: yttrium-based conversion coating; AZ91D magnesium alloy; rare earth; post-treatment; corrosion resistance

\section{FULL TEXT}

(C) 2017 The Authors. Published by ESG (www.electrochemsci.org). This article is an open access article distributed under the terms and conditions of the Creative Commons Attribution license (http://creativecommons.org/licenses/by/4.0/). 